\title{
Implementasi Kurikulum Muatan Lokal Vokasional
}

\author{
Baiq Lulu Ayu Widya Wijaya ${ }^{1}$, Abdul Huda ${ }^{2}$ \\ ${ }^{1}$ SLB Penujak Kabupaten Lombok Tengah \\ ${ }^{2}$ Universitas Negeri Malang \\ E-Mail: baiqluluayuwwijaya@gmail.com
}

\begin{abstract}
Abstrak:Tujuan penelitian ini adalah mendeskripsikan implementasi kurikulum muatan lokal di SLB Negeri Penujak, Penelitian menggunakan pendekatan kualitatif dengan jenis penelitian studi kasus. Pengumpulan data dilakukan dengan wawancara, observasi dan studi dokumentasi. Analisis data: Reduksi data, penyajian data, dan penarikan kesimpulan. Pengecekan keabsahan data triamngulasi data dan member check. Hasil penelitian Implementasi kurikulumyaitu persiapan materi, metode, instruktur, sarana dan prasarana. Kesimpulan penelitian ini adalah sekolah SLB Negeri Penujak melaksanakan kurikulum melalui proses pengembangan kurikulum, pelaksanaan kurikulum penilaian dan tindak lanjut walaupun masih banyak mengalami kendala.
\end{abstract}

Kata kunci: Implementasi, Kurikulum Muatan Lokal, Vokasional

\begin{abstract}
The purpose of this research is to know and describe the implementation of local content curriculum in SLB Penujak. The research was done with a case study qualitative. The data collection was done by interviews, observation and study documentation. The data technique analysis used (1) reduction, (2) the presentation of the display data, and (3) a conclusion and verification ofTo check the validity of data in this research using trianggulasi data and member check. The research results showed that: curriculum consist of the implementation of the materials preparation a method, instructors, facilities and infrastructure. Based on the research can be concluded that the special school Penujak had tried to implement curriculum of the process curriculum development, the implementation of the assessment and follow-up though still several problems.
\end{abstract}

Key words: Local content curriculum, Curriculum development, the implementation of curriculum

Pendidikan merupakan hal yang sangat penting dan berkaitan langsung dengan segala aspek kehidupan manusia, yang menyangkut setiap individu dengan kata lain pendidikan menentukan model manusia yang akan dihasilkannya. Pendidikan menempati posisi yang sangat strategis untuk membentuk manusia atau individu dalam pencapaian aktualisasi dirinya. Undang- Undang No.20 Tahun 2003 tentang Sistem Pendidikan Nasional yang berbunyi Pendidikan adalah "usaha sadar dan terencana untuk mewujudkan suasana belajar dan proses pembelajaran agar peserta didik secara aktif mengembangkan potensi dirinya untuk memiliki kekuatan spiritual keagamaan, pengendalian diri, kepribadian, kecerdasan, akhlak mulia, serta keterampilan yang diperlukan dirinya, masyarakat, bangsa dan negara".Paparan penjelasan undang-undang tersebut bahwa, pendidikan Nasional dilaksanakan melalui lembaga-lembaga pendidikan baik dalam bentuk sekolah maupun dalam bentuk kelompok belajar yang telah dirangkai secara sistematis untuk mencapai tujuan-tujuan. pendidikan Nasional. Undang-Undang nomor 20 Tahun 2003 Pendidikan selain sebagai usaha sadar dalam membentuk karakter masyarakat Indonesia, juga mempertegas komitmen pemerintah untuk melaksanakan pendidikan yang bermutu sebagaimana termuat dalam pasal 5 ayat (1)yang dirumuskan dalam kalimat berikut: "Setiap warga Negara mempunyai hak yang sama untuk memperoleh pendidikan yang bermutu". Dapat dipahami bahwa semua anak Indonesia bukan hanya wajib mengikuti pendidikan yang dibiayai sepenuhnya oleh pemerintah, melainkan juga berhak memperoleh pendidikan yang bermutu tidak terkecuali bagi anak berkebutuhan khusus, amanat hak atas pendidikan bagi penyandang kelainan ditetapkan pada pasal 32 "Pendidikan Khusus(Pendidikan Luar Biasa) yaknipendidikanbagi peserta didik yang memiliki tingkat kesulitan, dalam mengikuti prosespembelajaran disebabkan hambatan fisik, emosional, mental, sosial, dan atau memiliki potensi kecerdasan dan bakat istimewa". Ketetapan ini sebagai pijakan yang kuat bahwa anak-anak penyandang hambatan memperoleh hak dan kesempatan yang sama sebagaimana dalam hal pendidikan dan pembelajarannya. Untuk merealisasikan SDM yang unggul dan berkualitas, tentu diperlukan berbagai faktor penunjang yang tepat, salah satunya dengan pendidikan dan kurikulum. Salah satu kebijakan makro pemerintah yang paling esensial yakni memberlakukan undang-undang nomor 22 tahun 1999 tentang pemerintahan daerahmenggunakan pendekatan monolitik yang berbentuk bidang studi. Pengembangan kurikulum muatan lokal dimaksudkan untuk mengimbangikelemahan-kelemahan pengembangan kurikulum sentralisasi, dan bertujuan agar peserta didik 
mencintai sertamengenal lingkungannya.muatan seni budaya dan keterampilan sebagaimana yang diamanahi pada Peraturan Pemerintah Republik Indonesia No. 19
Tahun 2005 mengenai Standar Nasional Pendidikan, tidak hanya terwadahi pada satu bidang studi pelajara sebab budaya itu sendiri mencakup segala aspek kehidupan.

Menurut (Efendi, 2009)"Muatan lokal adalah programpendidikan yangisidanmediapenyampaiannya dikaitkan dengan lingkungan alam, lingkungan sosial dan lingkungan budaya serta kebutuhan daerah dan wajib dipelajari oleh siswa didaerah itu, dengan harapan agar potensi kekayaan alam dan budaya yang tidak rusak atau musanah", sedangkan pernyataan (Lestari, 2012). "kurikulum muatan lokal adalah rencana pengajaran yang bahan kajian dan pelajarannya diambil dari atau disesuaikandengan keadaan atau kondisi lingkungansetempat serta kebutuhan pembangunandaerah

Pemerintahan Daerah memberikan nuansa baru dalam pengelolaan pendidikan. Otonomi daerah dan wawasan demokrasi dalam menyelenggarakan pendidikan merupakan pengejawantahan dari undang-

Substansi muatan lokal ditentukan oleh satuan Substansi muatan lokal ditentukan oleh satuan
pendidikan. Muatan lokal merupakan kegiatan kurikuler untuk mengembangkan kompetensi yang disesuaikan dengan ciri khas dan potensi daerah,. Guru dan kepala sekolah merupakan salah satu kompon dan kelo yang paling
muatan lokal.

Pada Sekolah Luar Biasa sebagai lembaga pendidikan anak berkebutuhan khusus tentunya aka mengalami rodis besi serta dikaji secara mendalam untuk dibelajarkn kepado siswal yang akan disajikan karateristik don kebuthan siswa untuk jun denga yang panje sechak

Lo

Lombok Tengah adalah salah satu Kabupaten Nusa Tenggara Barat yang cukup unikkarena menjadi
daerah tujuan wisata.Daya tarik wisata yang dimiliki daerah tujuan wisata.Daya tarik wisata yang dimilik merupakan daya tarik wisata alam dan buday Pengembangan destinasi pariwisata Lombok Tenga tradisional, baik alam maupun budaya merupaka pemicu ekonomi yang memberikan dampak positif bagi perkembangan ekonomi masyarakat (Dinas Parwisata Lomb hal tersebt mendor SLB Negei Penuk jug hal tersebut mendorong SLB Negeri Penujak jug melalui kurikulum muatan lokal yang telah disusun dan dirang daerah, tida honya censia lokal mestaikan dan dikeman memperthankan nilai-nilai luhur bangsa Indonesia melalui upaya pengembangan kurikulum di sekolah.
SLB Negeri Penujak dengan muatan kurikulum berbasis kearifan Lokal budaya daerah.SLB Penuja dapat mengembangkan program ekstrakurikuler yang terkait dengan budaya, tradisi dan keunggulan lok daerah, diantara kegiatan yang dimaksud adalah kegiatan ekstrakurikuler meliputi pengembanga beberapa macam jenis keterampilan yang tela dicantumkan dalam kurikulum muatan lokal yan pertama menenun songket atau masyarakat Lombok menyebutkan dengan nama "Nyesek", kemudia Gerabah, Salon/ Tata rias, kemudian ruang Seni Voka Suara, dan membuat keset itu semua telah dirangkum didalam kurikulum sekolah tersebut. Sekolah tersebu juga memiliki banyak keunggulan dari hasil produk atauoutput hasil keterampilan siswa bisa dipasarkan tidak kalah bagus dengan buatan tangan individ regeluer. Siswa mengikuti pameran-pameran dari tingkat daerah hingga skala Nasional melalui menenu songket atau biasa dikenal dengan istilah nyesek Sekolah tersebut kerap kali dijadikan tempat elatiha keterampilan Vokasional untuk sekolah SLB di Lombok dan hasil karya siswa tidak kalah bagus untuk dipasarkan dengan buatan pabrik.Berdasarkan kontek penelitian di atas peneliti perlu mengkaji lebih lanju mengenai “Implementasi Kurikulum Muatan Lokal

\section{METODE}

Pendekatan penelitan yang digunakan penelitian kualitatif dengan jenis pendekatan studi kasus. Data yang diperoleh melalui wawancara mendalam (indepthinterwiew), partisipan observasi (participan observatif), dan studi dokumentasi kemudia dideskripsikan secara bahasa verba. peneliti sebagai instrumen kunci (key instrument). 1. Tekhnik analis data yang digunakan oleh peneliti mengacu pad pendapat Miles dan Hubernan (dalam terdapat 3 langka yang digunakan dalam proses analisis data ,antara lai (1) Reduksi data (Reduction), (2) Penyajian Da (Display data), dan (3) Kesimpulan dan Verifikas data (Conclusion and Drawing/ Verification)

Untuk mempermudah proses pengerjaannya langkah-langkah sebagai berikut : (1) Menuangkan transkrip wawancara, menulis catatan lapangan observasi, dan dokumentasi semua data yang
terkumpul disusun secara sistematis untuk terkumpul disusun secara sistematis untu data yang telah diperoleh dari hasil wawancara Observasi, dokumentasi yang diklasifikasikan dan direduksi dengan menonjolkan pokok-pokok pentingdan memberikan kode catatan lapangan, hal in dilakukan sebagai suatu proses analisis; analisis data bertujuan untuk mengelompokkan, mengarahkan, membuang data yang tidak perlu, analisis dilakuak secara berulang-ulang; (4) mememberikan intrepetasi, penyajian data (display data) kebermakanaan data bukti- bukti yang valid dan konsisten saat peneliti yang dikemukakan merupakan kesimpulan kredibel. Sementara itu (1) triangulasi data, mengunakan teknik sumbe yaitu menggali kebenaraninformai tertentu melalu erbagai motodo dan sumber perolehan data. dengan membandingkan data atau mengecek kebenaran data yang diperolah dari informan yang satu dengan informan yang lain dan tringulasi teknik (2) member check yaitu data harus dibenarkan oleh sumber atau informan lainnya. Data harus diakui dan diterima kebenarannya oleh sumber informasi

\section{HASILDAN PEMBAHASAN}

Hasil

Pengembangan kurikulum

Perencanaanpengembangan kurikulum muatan lokal vokasional di SLB Negeri Penujak merujuk kepada proses pengembangan kurikulum muatanlokal melalui berbagai proses yaitu : (1) identifikasi kebutuhan sekolah dan daerah, (2) menentukan bahan kajian kurikulum, (3) menentukan jenis muatan lokal serta tujuan dan (4) pengorganisasian.

Pelaksanaan

Pelaksanaan kurikulum muatan lokal di SLB Penujak . (1) Dalam pelaksanaan dan pengembangan kurikulum muatan lokal, tugas kepala sekolah adalah kirenakan kegiatan yang akan dikembangkan di sekolah bersama komite dan guru-guru untuk melaknkatuhan colo kepala seko hesali mor mensukseskan

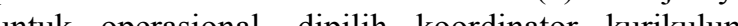
yang bertugas membantu kepala sekolah untuk yan , puru dan koordinator kurikulum saling bekerja sam, untuk penyur pere masing perre perencanan pemberajan, mulai dari tujun hinge pertama (a) menetapkan tujuan pembelajnra yang menggunan berbagi metode dolam mengair seperti ceramah, demonstrasi dll, (c) materi yang digunakn dibuat sendiri oleh masing-masing guru keterampilan sibuat sendiri oleh Penyampaian materi berdasilan prinsip pembelajaran $A B K$ yang mengikuti kegian keterampilan 6 orang siswa 4 tunagrahita ringen dan 2 tunarungu disesuaiakan, untuk tunarungu oral dan visual sedangkan tunagrahita individualisasi kegiat pembelajaran di mulai dari kegiatan awal, inti, dan akhir, dan (d) mengedepankan praktik langsung.
Penilaian

Menggunakan fortofolio tingkat perkembangan hsil belajar masing-masing siswa, melakukan praktik untuk menguji komptensi siswa dalam keterampilan. Tindak lanjut

Melakukan remdial materi yang masih belum dikuasai siswa, melakukan kerja sama dengan pihak luar menitipkan karya siswa di artshop/ pasar seni, mengikuti pameran dari tingkat Daerah- Nasional, kentian perk

Hambatan

Dalam pelaksanaan kurikulummuatan lokal kurangnya tenaga pengajar baik segi kuantitas dan kualitas untuk mengampu kegiatan pembelajaran sehingga ada beberapa kegiatan pembelajaran ada yang tidak berjalan dengan maksimal, bahan habis pakai untuk keterampilan, kurangnya alat dibandingkan peserta didik yang mengikuti kegiatan pembelajaran, kurang motivasi siswa sering mengalami kejenuhan, dan kurang dana untuk kegiatan keterampilan.

\section{Pembahasan}

Dalam pengembangan kurikulum mautan lokal di SLB penujak Melalui beberapa tahapan (1) identifikasi kebutuhan daerah, (2) penentuan bahan kajian kurikulum didasari sarana dan prasarana yang ada, tujuan kurikulum dll. Pernyataan sejalan dengan pernyataan dari(Warnadi, 2014)."Kurikulum muatan lokal adalah rencana pengajaran yang bahan kajian dan pelajarannya diambil dari atau disesuaikan dengan keadaan atau kondisi lingkungan setempat serta kebutuhan pembangunan daerah", sedangkan (Efendi,2009) mengungkapkan langkah-langkah mengidentifikasi daerah dilakukan untuk menelaah dan mendata berbagai keadaan dan kebutuhan didaerahnya. Pelaksanaan pembelajaran di SLB Penujak (I) Tujuan pembelajaran yang ditetapkan oleh guru di SLBkegiatan keterampilan, harapan setelah pembelajaran keterampilan peserta didik mampu menerapkan keterampilan yang dipelajari, penetapan tujuan pechbelajan sestai dengan potensi siswa. (2) Metode pembelajaran di SLB Negeri Penujak menggunakan metode ceramah dan demonstrasi. (3)Praktik, Siswa di SLB Negeri Penujak dalam keterampilannya lebih kepada praktikProses pembelajaran muatan lokal menekankan praktik langsung dan fungsional, hal ini sejalan dengan pendapat ahli yang dikemukaan oleh (Ishartiwi, 2010) bahwa belajar tindakan membutuhkan parktik atau latihan sebab mengharuskan gerakan yang tepat yang telah diasosiasikan dengan petunjuknya. Keterampilan yang syarat dengan gerakan untuk menghasilkan suatu tindakan dan juga menghasilkan produk karya hasil belajar ini menurut Teori Bloom dominan pada ranah 
psikomotor, meskipun tercakup juga dua ranah belajar lainnya, yairu kognitif dan afektif (Winkel, 2007).

\section{Penilaian dan Tindak Lanjut}

Penilaian

Kegiatan keterampilan di SLB Negeri Penujak menggunakan tes dan non te. Non tes penilaian berupa deskriptif hasil perkembangan belajar siswa sedangkan tes berbentuk praktik. Menurut (Zainul dan Nasution:2002) mengartikan penilaian adalah suatu proses untuk mengambil keputusan dengan menggunakan informasi yang diperoleh melalui pengukuran hasil belajar baik yang menggunakan tes maupun nontes.

Tindak lanjut

Di SLB Negeri Penujak Lombok Tengah tindak lanjut yang dilakukan oleh guru adalah melakukan pengulangan materi (remidial) materi yang belum dikuasai siswa hasil penilaian dari guru tersebut,ini dilakukan guru agar siswa mampu menguasi seluruh materi yang diajarkan dengan baik, hasil karya siswa atau produk SLB Negeri Penujak melakukan kerjasama dengan pihak luar untuk mempromosikan produk, selanjutnya dijual di artshop, mengikuti pameranpameran dan sebagai pembina kegiatan nyesek seNTB.

\section{Hambatan}

Adapun hambatan pelaksanaan di SLB Negeri Penujak berdasarkan hasil temuan yaitu sebagai berikut: (1) Hambatan yang dialami pada saat keterampilan siswa kurang motivasi dalam belajar hal ini bisa disebabkan karena faktor materi keterampilan yang tidak variatif melakukan pengulangan, karena karakterisitk siswa anak berkebutuhan khsusus yang mudah mengalami kejenuhan. (2) Kurangnya tenaga pengajar, seperti halnya yang kita ketahui bahwa keterampilan muatan lokal terdiri dari berbagai macam pilihan materi sesuai dengan keadaan dan kebutuhan daerah serta satuan pendidikannya, sehingga membutuhkan banyak tenaga pengajar dari berbagai keahlian, oleh karena itu kurangnya tenaga pengajar (baik dari segi jumlah dan kualitas) akan mengakibatkan kurang efektif kegiatan keterampilan sehingga ada beberapa kegiatan keterampilantidak berjalan dengan baik. Hambtan selanjutnya (3) Terbatasnya alat, bahan dan dana Sarana dan prasarana termasuk hal yang esensial dalam menunjang kelancaran implementasi di SLB Negeri Penujak yang dimaksud tersebut, dapat berupa bahan untuk keterampilan, juga alat pembelajaranketerampilan jumlahnya kurang banyak.

\section{KESIMPULAN DAN SARAN}

\section{Kesimpulan}

Dapat disimpulkan bahwa sekolah SLB Negeri Penujak melaksanakan kurikulum melalui proses pengembangan kurikulum, pelaksanaan kurikulum penilaian dan tindak lanjut walaupun masih banyak mengalami kendala.

\section{Saran}

Rekomendasi penting disarankan yaitu:(1) Pemerintah membuat kebijakan baru merekrutkmen guru bidang studi muatan lokal, menyususn anggaran dana untuk kurikulum muatan lokal,(2) Hendaknya pihak sekolah mampu menentukan kegiatan kurikulum yang tepat untuk mengisi kurikulum muatan lokal di lembaganya berdasarkan pertimbangan secara matang kompetensi tenaga pengajar, (3) Kepala Tata Usaha sekolah lebih memperluas jaringan kerjasama untuk mempromosikan dan memasarkan karya siswa melalui social media, (4) Guru Keterampilan hendaknya membuat perencanaan yang sistematis dan kreativ dalam mengelola kegiatan pembelajaran sehingga siswa tidak jenuh.

\section{DAFTAR RUJUKAN}

Asmawi Z \& Nasution N. (2001). Penilaian Hasil Belajar. Jakarta: Irjen Dikti.

Depdiknas. (2006). Kurikulum Tingkat Satuan Pendidikan 2006. Jakarta

Efendi, M. (2009). Pengantar Psikopedagogik Anak berkelainan.Jakarta: PT Bumi Aksara

Efendi, (2009). Kurikulum Pembelajaran. Malang: Universitas Negeri Malang.

Ishartiwi. (2010) .Pembelajaran Keterampilan Untuk PemberdayaanKemandirian Anak Berkebutuhan .Yogyakarta: Jurnal PLB, Vol 4

Lestrasi, S. (2012). Pengelolaan Kurikulum Muatan Lokal (kml) Bahasa Inggris SD Negeri seKecamatan Gondokusuman Yogyakarta: Jurnal Penelitian Ilmu Pendidikan Vol 2, No.2

Sugiyono. (2001). Metode Penelitian Kuantitatif, Kualitatif Dan R\&D, Alfabeta. Bandung.

Warnadi, N. (2014). Implementasi Pengembangan Kurikulum Muatan Lokal Pada Sekolah Luar Biasa. Disajikan dalam seminar Internasional PLB, Bandung.

Winkel. (2007). Psikologi Pendidikan dan Evaluasi Belajar. Jakarta: PT. Gramedia.

Yamin, M. (2012). Manajemen Berbasis Sekolah. Jakarta: Referensi. 